\title{
TRAUMATIC SHOCK. X. THE TREATMENT OF HEMORRHAGIC SHOCK IRREVERSIBLE TO REPLACEMENT OF BLOOD VOLUME DEFICIENCY ${ }^{1}$
}

\author{
By HOWARD A. FRANK, ARNOLD M. SELIGMAN, AND JACOB FINE \\ (From the Surgical Research Department, Beth Israel Hospital, and the Department of Surgery, \\ Harvard Medical School, Boston)
}

(Received for publication August 15, 1944)

Since loss of blood volume is the initiating factor common to most types of traumatic shock, the therapeutic problem has been studied experimentally primarily from this point of view. Confusing or complicating factors, such as local trauma and the sepsis of trauma and anesthetics including barbiturates, have been eliminated by limiting the experimental method to simple hemorrhage in the unanesthetized animal, with or without morphine. Shock, so induced and maintained, exhibits all the classical phenomena expected and is responsive within certain variable limits of time and levels of blood pressure, to the restoration of all the shed blood. If the shock state is treated effectively first by a replacement of the blood volume deficiency, the shock is said to be "reversible" and as such does not represent a problem of challenging import. The problem, for our purpose, begins when and if the replacement of all shed blood, by whole blood or a blood substitute, fails to produce a sustained improvement equivalent to virtual recovery. This communication is concerned with the therapeutic value of a variety of agents administered after the shock has been shown to be irreversible to the infusion of all shed blood. This we regard as the most valid technique for testing the efficacy of any agent. $^{2}$

1 The work described in this paper was done under a contract, recommended by the Committee on Medical Research, between the Office of Scientific Research and Development and Harvard University.

2 The existence of a state of irreversibility to transfusion can be only roughly estimated (see below) because age, condition of the experimental animal, nutritional and fluid reserve, environmental temperature, position on the table, etc. influence the progress of the shock state. Since no reliable method for confidently predicting the response to blood or blood substitute alone has been developed, claims made for the therapeutic value of any procedure or any substance other than blood or a blood substitute could be valid if effective alone and without restoring blood

\section{METHOD}

Unselected mongrel dogs weighing from 8 to $20 \mathrm{kgm}$. were given a single dose of morphine sulphate ( 1 to 2 $\mathrm{mgm}$. per $\mathrm{kgm}$. intramuscularly) 1 to 2 hours before the start of the experimental period. Groin vessels were exposed after procaine infiltration with a minimum of dissection and blood loss and without aseptic precautions. Sulfanilamide powder or propamidine cream was put in the wound at the end of the dissection and again just before closure. No other wound was created, except for an occasional exposure of the left external jugular vein, through which a tube or catheter was passed to the right auricle for sampling the mixed venous blood or measuring the venous pressure. The arterial blood pressure was measured by a mercury manometer attached to a heparinized cannula in the femoral artery. The animals were handled gently and were lightly tied to the table. The position of the thorax was changed frequently during the shock period and after therapy. In a prolonged course of therapy, occasional animals were removed from the table now and then and allowed to walk about.

The animals were bled rapidly from the femoral artery into clean but unsterilized vessels containing heparin. Since unanesthetized dogs may tolerate blood pressure levels as low as $50 \mathrm{~mm}$. $\mathrm{Hg}$ for long periods (in occasional instances for as long as 5 to 8 hours) without developing irreversible shock, bleeding was continued until the blood pressure dropped to $30 \mathrm{~mm}$. $\mathrm{Hg}$ and maintained within a range of 30 to $50 \mathrm{~mm} . \mathrm{Hg}$ by subsequent small withdrawals or reinfusions of blood. The amount of bleeding required to accomplish this fall varied from 20 to $60 \mathrm{ml}$. per $\mathrm{kgm}$. Subsequent spontaneous drops in blood pressure below $30 \mathrm{~mm}$. $\mathrm{Hg}$ were apt to result in cessation of respiration and death, even though shock irreversible to transfusion might not have supervened. These were treated by the infusion of enough blood to raise the blood pressure to just above $30 \mathrm{~mm}$. $\mathrm{Hg}$ and to maintain spontaneous respiration. When, after a period varying from 1 to 5 hours, there was little or no response of blood pressure to small test transfusions of 25 to $50 \mathrm{ml}$. of blood, irreversibility to transfusion was likely, though

volume deficiency or if effective after a transfusion has failed. If the estimate of an agent's value is based upon its presumed effectiveness when given just before or along with the blood or blood substitute, unequivocal evidence must be provided to show that the latter alone would not have achieved the same result. 
not certainly predictable. When the dog was thought to be irreversible to transfusion the remainder of the withdrawn blood was filtered through gauze and rapidly infused into the femoral vein. The blood pressure response was then followed. If the condition of an animal was so poor at the end of the shock period that it did not respond to transfusion with a rise in blood pressure to 80 to 100 $\mathrm{mm}$. $\mathrm{Hg}$ or higher, it was not used. If the animal recovered completely or maintained a blood pressure level above $80 \mathrm{~mm}$. $\mathrm{Hg}$ for more than 3 to 4 hours, it was discarded. Only when the blood pressure fell to $70 \mathrm{~mm} . \mathrm{Hg}$ or less was irreversibility to transfusion assumed and a test of supplementary therapy started. (The only deviation from this procedure occurred in the group of dogs (Group F) which were treated by sodium bicarbonate dissolved in the transfused blood.) In some experiments, therapy was continued until the animals were clearly moribund or dead; in others, the groin wounds were closed upon termination of therapy and the animals were taken down from the tables. The thoracic and abdominal viscera were examined as soon as possible after death.

In about half of the experiments herein reported, it was found convenient to use an apparatus (1) which is arranged to permit bleeding freely into a bottle suspended at a level corresponding to $30 \mathrm{~mm}$. $\mathrm{Hg}$ pressure, so that a rise in arterial pressure above $30 \mathrm{~mm}$. $\mathrm{Hg}$ results in further bleeding into the bottle, while a fall below $30 \mathrm{~mm}$. $\mathrm{Hg}$ results in back-flow from the bottle into the artery. This steady level of blood pressure is maintained for hours. Sulfanilamide (0.8 gram per $100 \mathrm{ml}$. of shed blood) and just enough heparin to prevent coagulation were added to the blood in the bottle. With this set-up, irreversibility was considered likely when one third to one half of the blood in the bottle had returned to the dog. The remaining blood was then rapidly infused into the femoral vein. The automaticity of this apparatus made it possible to run as many as 6 experiments simultaneously, so that a group of dogs could be observed under identical environmental conditions.

Since dogs in shock are susceptible to further damage from almost any manipulation, no procedures other than those described were carried out, and blood sampling was almost entirely avoided.

\section{TECHNIQUES OF THERAPY AND RESULTS}

\section{Group A: Physiologic saline solution}

Five dogs were given 0.85 gram per cent sodium chloride solution intravenously, continuously or intermittently at whatever rate was required to maintain the blood pressure above 80 $\mathrm{mm} . \mathrm{Hg}$. If the response was adequate, the rate of injection was controlled so as to minimize overloading of the circulation. If the response was not sustained, the infusion was continued without interruption until the moment of death. The total volume of saline solution given ranged from 75 to $885 \mathrm{ml}$. per $\mathrm{kgm}$. Transitory improvement of the circulation resulted, as indicated by the rise in arterial blood pressure and the oxygen content of venous blood, but all dogs died within 18 hours after the start of this supplemental therapy. Marked generalized and pulmonary edema, serous effusions, and intestinal hemorrhages were found at post-mortem examination. In many instances, the liver was stiff and swollen, the leaves of mesentery and the lobules of pancreas were separated, and the subcutaneous tissues were tense with fluid.

\section{Group B: Ringer's solution with glucose and alkali $^{3}$}

This preparation was used instead of saline solution in this group to counter a possible deficiency in carbohydrate and the increase in acid metabolites. Six dogs so treated received the fluid after the manner described for Group A, with the same transitory improvement produced by saline solution. All 6 dogs died within 16 hours after the start of this therapy and showed the same autopsy findings as in Group A.

\section{Group C: 5 per cent crystallized bovine albumin ${ }^{4}$}

Thirteen dogs received this therapy continuously until they maintained improvement or until they were moribund. The total volume given ranged from 80 to $250 \mathrm{ml}$. per $\mathrm{kgm}$. In 8 experiments, the albumin was dissolved in 0.85 per cent saline solution; in 5 , the albumin was dissolved in the modified Ringer's solution with added glucose and alkali. Temporary improvement in arterial blood pressure and venous blood oxygenation resulted in almost all dogs. Ten died within 24 hours of the start of treatment. One dog, receiving albumin in saline solution, lived 48 hours and one dog, receiving albumin in Ringer's solution, recovered completely.

Marked oozing of blood from all wounds appeared soon after the beginning of the albumin infusion. It could not be controlled by pressure, wound suture, or thrombin solution.

At autopsy, all animals of the group showed

\footnotetext{
8 Composition of this fluid per liter distilled water: $\mathrm{NaCl} 8.5$ grams, $\mathrm{NaHCO}_{3} 4.0$ grams, $\mathrm{KCl} 0.4$ gram, $\mathrm{CaCl}_{2} 0.2$ gram, Glucose 50.0 grams.

\& Supplied by Armour \& Co. through the courtesy of Dr. E. J. Cohn of the Harvard Medical School, Boston.
} 
Therapy of "irreversible" hemorrhagic shock

\begin{tabular}{|c|c|c|c|}
\hline Nature of therapy & $\begin{array}{c}\text { Dogs } \\
\text { treated }\end{array}$ & $\begin{array}{c}\text { Sur- } \\
\text { vivors }\end{array}$ & Remarks \\
\hline $\begin{array}{l}\text { A. } 0.85 \text { per cent sodium } \\
\text { chloride solution } \\
75 \text { to } 885 \text { ml. per } \mathrm{kgm} \text {. }\end{array}$ & 5 & $\mathbf{0}$ & $\begin{array}{l}\text { Rise in venous blood oxygenation with rise in blood pressure. Apparent pro- } \\
\text { longation of life, but all dead within } 18 \text { hours of start of therapy. General- } \\
\text { ized and pulmonary edema, serous effusions, intestinal hemorrhages. }\end{array}$ \\
\hline $\begin{array}{l}\text { B. Ringer's solution with } \\
\text { glucose and alkali* } \\
80 \text { to } 200 \text { ml. per kgm. }\end{array}$ & 6 & 0 & $\begin{array}{l}\text { Looked better while being treated than did dogs in Group A. None sur- } \\
\text { vived longer than } 16 \text { hours after start of therapy. Autopsy findings as in } \\
\text { Group A. Less pulmonary edema. Livers looked better. }\end{array}$ \\
\hline $\begin{array}{l}\text { C. } 5 \text { per cent crystallized } \\
\text { bovine albumin } \\
80 \text { to } 250 \text { ml. per kgm. } \\
\text { Dissolved in saline } \\
\text { Dissolved in Ringer's } \\
\text { solution with glucose } \\
\text { and alkali * }\end{array}$ & $\begin{array}{l}8 \\
5\end{array}$ & $\begin{array}{l}0 \\
1\end{array}$ & $\begin{array}{l}\text { Rise in blood pressure and venous blood oxygen content. Apparent pro- } \\
\text { longation of life, but } 7 \text { died within } 24 \text { hours. Pulmonary, hepatic, and } \\
\text { intestinal congestion and edema. Bloody serous effusion. Hemorrhagic } \\
\text { intestinal mucosa. Subserosal and subepicardial hemorrhage. General- } \\
\text { ized bleeding (not controlled in wounds by thrombin). }\end{array}$ \\
\hline $\begin{array}{l}\text { D. } 25 \text { per cent bovine al- } \\
\text { bumin in saline } \\
20 \text { to } 89 \mathrm{ml} \text {. per } \mathrm{kgm} \text {. }\end{array}$ & 10 & 0 & $\begin{array}{l}\text { Small rise in blood pressure. Little apparent effect on course. Dry tissues } \\
\text { and serous surfaces. No intestinal hemorrhages ( } 4 \text { dogs). }\end{array}$ \\
\hline $\begin{array}{l}\text { Physiologic saline } \\
\text { given subsequently } \\
50 \text { to } 150 \mathrm{ml} \text {. per } \mathrm{kgm} .\end{array}$ & 6 & $\mathbf{0}$ & $\begin{array}{l}\text { Addition of saline led to some improvement in blood pressure. Develop- } \\
\text { ment of wet tissues after added saline. Hemorrhage from wounds with } \\
\text { rise in blood pressure. All dogs dead within } 18 \text { hours after start of therapy. }\end{array}$ \\
\hline $\begin{array}{l}\text { E. Succinic acid (neutral- } \\
\text { ized) } \\
1 \text { gram per kgm. in } \\
\text { saline }\end{array}$ & 13 & 0 & $\begin{array}{l}\text { Occasional small rises in blood pressure. No improvement in venous blood } \\
\text { oxygen content. No suggestion that survival time was prolonged. }\end{array}$ \\
\hline $\begin{array}{l}\text { F. Sodium bicarbonate } \\
1 \text { gram per kgm. dis- } \\
\text { solved in transfusion } \\
\text { blood }\end{array}$ & 7 & 0 & $\begin{array}{l}\text { Acidosis corrected but poor response to transfusion. All dead within } 4 \\
\text { hours. No striking pathology. }\end{array}$ \\
\hline $\begin{array}{l}\text { G. Pitressin } \\
0.4 \text { to } 4.0 \text { pressor units } \\
\text { given fractionally plus } \\
\text { Ergotamine } 0.2 \text { to } 0.4 \\
\text { mgm. }\end{array}$ & 10 & $\mathbf{0}$ & $\begin{array}{l}\text { (All dogs previously treated in Group E.) Small and brief rises in blood } \\
\text { pressure. No improvement in venous blood oxygen content. No signifi- } \\
\text { cant prolongation of survival. Frequent convulsions. Marked blanching } \\
\text { and contraction of intestines seen at autopsy. All died within } 12 \text { hours. }\end{array}$ \\
\hline $\begin{array}{l}\text { H. Pitressin } 0.5 \text { to } 1.0 \\
\text { pressor units in } 5 \text { per } \\
\text { cent bovine albumin } \\
50 \text { to } 80 \mathrm{ml} \text {. per } \mathrm{kgm} \text {. }\end{array}$ & 5 & $\mathbf{0}$ & All dead within 10 hours after start of therapy. \\
\hline $\begin{array}{l}\text { I. Paredrine } \\
20 \text { to } 40 \text { mgm. }\end{array}$ & 6 & 0 & $\begin{array}{l}\text { Rise in venous pressure with rise in arterial. No improvement in cardiac } \\
\text { output. Duration of effect limited to about } \mathbf{4 0} \text { minutes. }\end{array}$ \\
\hline $\begin{array}{l}\text { J. Coramine fractionally } \\
\text { to } 0.25 \text { gram }\end{array}$ & 4 & $\mathbf{0}$ & $\begin{array}{l}\text { Rise in skeletal muscle tonus to rigidity and convulsions. Inconstant rise in } \\
\text { auricular pressure. No improvement in venous blood oxygen content. } \\
\text { No rise in arterial blood pressure. No clinical evidence of improvement } \\
\text { (All dogs previously treated in Group I). }\end{array}$ \\
\hline $\begin{array}{l}\text { K. Tuamine } \\
3 \text { mgm. per kgm. }\end{array}$ & 6 & $\mathbf{0}$ & $\begin{array}{l}\text { Increase in arterial pressure but no rise in cardiac output. Duration of effect } \\
\text { limited to } 10 \text { to } 20 \text { minutes and subsequent injections ineffective. No } \\
\text { characteristic gross pathology. }\end{array}$ \\
\hline $\begin{array}{l}\text { L. Potassium phosphate } \\
\text { solution } \\
1 \text { to } 3 \mathrm{ml} \text {. given intra- } \\
\text { cisternally }\end{array}$ & 4 & 0 & Elevation in blood pressure without prolongation of survival time. \\
\hline
\end{tabular}

* Composition of Ringer's solution with glucose and alkali, per liter distilled water: $\mathrm{NaCl} 8.5$ grams, $\mathrm{NaHCO}$ 4.0 grams, $\mathrm{KCl} 0.4$ gram, $\mathrm{CaCl}_{2} 0.2$ gram, $\mathrm{MgCl}_{2} 0.2$ gram, Glucose 50.0 grams.

marked venous congestion of lungs, liver, kidney, mesentery, and gastro-intestinal tract, and large effusions in the pleural, pericardial, and peritoneal sacs. Many of these effusions were grossly 
bloody and there were frequent sub-pleural, subepicardial, and sub-peritoneal hemorrhages. Although the tissues were wet, the extreme edema of saline treated dogs was not seen.

\section{Group D: 25 per cent bovine albumin in saline}

Ten dogs were given 20 to $89 \mathrm{ml}$. per $\mathrm{kgm}$. of a 25 per cent solution of crystallized bovine albumin in saline solution. The resulting rise in blood pressure was slight and there was little apparent effect on the shock state.

Four dogs died without further treatment. At autopsy, the tissues and serous surfaces were dry and there was no hemorrhage in the intestine or elsewhere.

In the remaining 6 dogs, when it was clear that no benefit had resulted from the albumin solution, supplementary physiologic saline solution was given intravenously, in doses ranging from 50 to $150 \mathrm{ml}$. per $\mathrm{kgm}$. Some improvement in blood pressure resulted, but all dogs were dead within 18 hours of the start of therapy. These dogs showed wet tissues at autopsy. With improvement in blood pressure, whether resulting from albumin solution alone or following the supplementary saline, marked bleeding from wounds occurred.

Group E (See Group G below): Succinic acid

Thirteen dogs were given sodium succinate ( 1 gram per $\mathrm{kgm}$.) in 0.85 per cent saline solution, intravenously. Occasional small rises in arterial blood pressure followed these injections, but no rise in venous blood oxygen content was observed. When the results of therapy were clearly disappointing, further therapy, described under Group $\mathrm{G}$, was given. All 13 dogs died without evidence that the survival time was prolonged.

\section{Group F: Sodium bicarbonate}

Seven dogs were given sodium bicarbonate (1 gram per $\mathrm{kgm}$.) dissolved in the shed blood before reinfusion. In several instances, mild hemolysis due to the salt was noted. The blood $\mathrm{CO}_{2}$ combining capacity showed that acidosis was corrected and did not return. The response to transfusion plus sodium bicarbonate was poor and all dogs were dead within 4 hours after transfusion. There was no remarkable feature in the gross pathology of the viscera.
This is the only group in which the therapeutic agent was given before the response to transfusion alone had been observed.

\section{Group $G$ (See Group E): Pitressin and ergotamine}

Thirteen dogs which had previously been unsuccessfully treated with succinic acid (Group E) were given repeated injections of pitressin, the total dose ranging from 0.4 to 4.0 pressor units. The injections were followed by small and brief rises in blood pressure without improvement in venous blood oxygenation. Ten of these dogs also received 0.2 to $4.0 \mathrm{mgm}$. of ergotamine. Generalized convulsions were seen frequently. There was no evidence of prolongation of survival time. All 13 dogs were dead within 12 hours after the start of therapy. Marked blanching and contraction of the intestine were seen at autopsy.

\section{Group H: Pitressin in 5 per cent bovine albumin}

Five dogs were each given 0.5 to 1.0 pressor unit of pitressin, dissolved in 50 to $80 \mathrm{ml}$. per $\mathrm{kgm}$. of 5 per cent bovine albumin. No significant improvement was noted and all dogs were dead within 10 hours of the start of therapy.

Group I (See Group J): Paredrine (p-hydroxy$a-m e t h y l p h e n y l e t h y l a m i n e ~ h y d r o b r o m i d e)$

Six dogs were given paredrine in repeated injections. The total dose was 20 to $40 \mathrm{mgm}$. Rises in arterial and venous blood pressure resulted but without improvement in cardiac output. The pressor effect lasted some 40 minutes and subsequent re-injection produced no response. All 6 dogs died several hours thereafter.

\section{Group J (See Group I): Coramine (pyridine- beta-carboxylic acid diethylamide)}

Four dogs which had become unresponsive to paredrine (Group I) were given repeated injections of coramine, reaching a total dose of 0.25 gram. An increase in skeletal muscle tone occurred, culminating in generalized rigidity and convulsions following the last injection. The doses of coramine just short of producing convulsions produced inconstant rises in right auricular pressure, no improvement in venous blood 
oxygen content, no rise in arterial blood pressure, or any other evidence of improvement.

\section{Group $K$ : Tuamine (2-aminophetane sulfate)}

Six dogs were treated after transfusion with tuamine given intravenously in a dose of $3 \mathrm{mgm}$. per $\mathrm{kgm}$. Of these, 2 were given the drug at a time when the blood pressure was still about 90 $\mathrm{mm}$. $\mathrm{Hg}$, that is; before irreversibility had been demonstrated by relapse into shock. The remaining 4 were treated in the usual fashion, after the increased blood pressure had again fallen to $70 \mathrm{~mm}$. Hg. All 6 dogs died. The observed effects of the drug were an increase in arterial blood pressure, in pulse rate, and in rate and depth of respiration; but no rise in cardiac output was observed. The duration of effect was limited to 10 to 20 minutes and subsequent injections produced no response. The gross post-mortem findings did not differ from those of irreversible hemorrhagic shock treated by transfusion alone.

\section{Group L: "Potassium phosphate" given intra- cisternally ${ }^{\circ}$}

Four dogs were given "potassium phosphate" by intra-cisternal injection when shock had recurred after transfusion. An injection of $1 \mathrm{ml}$. resulted in a marked rise in arterial blood pressure accompanied by nystagmus, proptosis, and stiffening of the neck and back muscles. Subsequent injections to $3 \mathrm{ml}$. produced no further rise in blood pressure and were followed by cessation of respiration. Doses of $0.3 \mathrm{ml}$., however, given repeatedly elicited responses in blood pressure over a period of 1 to 2 hours. The effect on the cardiac output was not measured. More extensive investigation was prevented by the small amount of material available. All dogs in the group died and there was no evidence that the survival time was prolonged by the treatment. Post-mortem examination of the spinal cord and brain was not done.

\section{DISCUSSION}

Earlier work from this laboratory $(2,3,4)$ has

5 We are indebted to Dr. Irvine H. Page for this material.

- We are indebted to Dr. Baird Hastings for this material which he obtained on a recent visit to Russia where it was said to have been beneficial in the therapy of shock. Its exact composition is unknown. demonstrated that the failure of transfusion to restore the animal in hemorrhagic shock is not due to loss of the restored fluid through abnormally permeable capillaries. It has long been clear that restoration of normal blood volume alone is incapable of reversing the deteriorating course of advanced hemorrhagic shock. The experiments herein reported, in which relatively enormous volumes of 5 per cent bovine albumin were infused after the initial transfusion, show that even sufficiently sustained increases in blood volume (to twice or three times normal) do not cure hemorrhagic shock which is irreversible to an initial blood transfusion.

Others $(5,6)$ have considered the problem from a simple mechanistic view and presented data to the effect that the deteriorating trend in shock in any stage can be halted or even reversed by the simple expedient of intravenous physiological saline solution, provided it is given in sufficient volume and for a sufficient length of time with care to avoid fatal pulmonary edema. One author explained the survival of his animals as due to the creation of a sufficiently high interstitial pressure to reverse the flow of fluids from out to into the circulatory bed. This postulate cannot apply to the type of shock which exists in the presence of an adequate blood volume and is therefore applicable only in the special circumstances of his experiments. The therapeutic value of the saline solution is not confirmed by our data on hemorrhagic shock even though the volume of saline solution was adequate to achieve the tissue pressures demanded by such a postulate. Furthermore, the futility of infusion of relatively huge volumes of fluids which escape only slowly from the circulation (albumin solution) makes it quite clear that when there is no continuing local loss of fluid into a damaged area, the shock state, even though initiated by a loss of blood or plasma, results in the development of changes that are no longer reversible by restoration and maintenance of a normal or more than normal blood volume.

Certain workers (7) burned dogs by immersion in hot water. Death resulted in a few hours if no treatment was given and survival was only slightly prolonged by treatment with saline solution. Longer survival was achieved by saline and soda bicarbonate solution. If plasma was added to this 
latter therapy, no substantial benefit was conferred. But if defibrinated blood was added, recovery from the immediately lethal effects resulted until the late secondary effects of tissue damage set in. They explain these results as follows: Saline solution alone may be expected to be useless since the plasma loss is not compensated for. The advantage of adding soda bicarbonate lies in its correction of the acidosis and in the supplying of additional sodium ion. Plasma given with chloride-bicarbonate solution is not effective because, they believe, the plasma leaks out too rapidly, not only into the burned area but into other tissues, so that not only is blood volume not sustained, but edema of the brain and lungs "due to plasma" will produce lethal effects. Since red cells do not leave the blood stream, defibrinated blood maintains blood volume while the chloridebicarbonate solution restores normal interstitial fluid and electrolyte balance.

To show that plasma is inferior to blood in these circumstances would require the use of larger quantities than were given. The assumption that plasma is futile because plasma leaves the circulation very rapidly when the plasma volume is normal does not imply that it will leave as rapidly when the plasma volume is deficient. There is no evidence to show that large quantities of plasma per se produce edema of the lungs or brain. When such edema has been observed, it has occurred only when saline has been given along with it, and the saline is admittedly a more obvious cause of such edema. In numerous experiments on the treatment of hemorrhagic shock, plasma alone was not observed to produce edema until the prelethal phase of shock had arrived and then only when saline solution was added. In these circumstances, edema and bleeding into tissues were observed also if whole blood was used instead of plasma.

In any event, conclusions drawn from the treatment of the acute hemodynamic imbalance of burns by these agents are not valid for simple hemorrhagic shock, since our therapy for the latter condition included the use of whole blood plus saline and soda bicarbonate (plus other normal electrolytes) with no appreciable benefit. Moreover, the infusion of large amounts of albumin or blood with saline or Ringer's solution containing alkali leads to uncontrollable hemorrhage in open wounds and in the intestine.

Since the restoration of normal circulation is a prerequisite to recovery of tissue function, one may take as early evidence of recovery from shock -aside from restoration of normal blood volume -a rise in cardiac output, an acceleration of capillary flow, a rise in oxygen content of the mixed venous blood, and a rise in blood pressure. Such changes are readily achieved during the early shock phase while it is still reversible to transfusion. Such changes also are achieved readily in the late phase of shock by the intravenous infusion of almost any compatible fluid. But these changes do not persist after the infusion has stopped or even while the infusion is continued. Since this is the case even if the blood volume replacement is adequate, the critical deficiency must be elsewhere within or outside the circulatory apparatus.

Evidence has been provided (8) of declining myocardial efficiency in the late shock phase. Recently, another worker (9) identified by ballistographic observations on the exposed heart a measure of cardiac weakness which was not reversible by any known methods of therapy except certain aliphatic amines ("one-amine," "tuamine," etc.) with specific myocardial stimulating qualities. In 6 experiments with our technique of determining irreversibility, tuamine produced no rise in cardiac output or other beneficial response except a transient rise in systolic pressure. The effect of tuamine was analogous to that of paredrine. Our experiments differed from those mentioned above in that there the drug was given with or immediately after transfusion, whereas we withheld the drug until the response to transfusion alone could be determined.

The fault in the circulation in shock has been attributed (10) to a loss of skeletal muscle tone with consequent failure of venous pressure and return flow. Paredrine constricts arteries and veins and raises pressure in both (11). But improved blood flow does not result, as cardiac output measurements (11) and capillary microscopy of omental vessels ${ }^{7}$ indicate. The evidence does not contra-

\footnotetext{
7 Unpublished data.
} 
dict the above postulate, which can only be tested by an agent which maintains unrestricted capillary inflow while increasing venous pressure. Coramine increases intramuscular pressure (12). In our experiments with coramine, skeletal muscle tone was increased to the point of extreme rigidity without improving blood flow. A more desirable physiological technique to test the hypothesis would provide for alternating contraction and relaxation of muscle.

Some authors (13) believe that the primary deficiency lies in the collapse of the contractile power (vasomotion) of arterioles and venules, which in late shock lose their reactivity to adrenalin. While no specific agent capable of restoring vasomotion has become available, the favorable response reported by them (14) from the use of pitressin with and without ergotamine was not substantiated by our experiments. They gave these agents with the first transfusion as well as subsequently. As already stated, we do not regard this method of testing the efficiency of any agent on the course of the shock state as valid unless it is given without transfusion or after the transfusion is shown to be ineffective.

While the critical deficiency in late shock may lie in an altered physiology of the circulation independent of controlling factors from outside of the circulation, it is natural that such controlling factors should also come under scrutiny, since the effect of inadequate blood flow is all-embracing. Ample evidence of serious disturbance of kidney (15), liver $(16,17)$, and intestinal (18) function and of extensive biochemical abnormalities, especially in intermediary carbohydrate metabolism (19), is available. Certain investigators (15) have succeeded in defining the limits of anoxia which the kidney can endure before irreparable damage to function results. But the effects of loss of kidney function, while capable of causing death within a few days, are not, as far as is known, operative within the shock period. Collapse of liver function might well result in irretrievable effects and death within the shock period. This problem is now under intensive investigation. We have found in work to be published from this Laboratory (17) that the maintenance of the circulation of the liver of the dog in shock by cross circulation with a healthy donor animal, prevents the development of "irreversible" hemorrhagic shock under experimental circumstances similar to those described in this report.

Uncompensated acidosis has long been known to persist in the untreated late shock phase and the alkali therapy introduced (20) during the first World War has most recently been recommended by others (21), who attribute to sodium bicarbonate the capacity to reverse and to cure a degree of shock not amenable to transfusion alone. They accept as a test for such a degree of shock not the fact of a futile transfusion already given, but a $\mathrm{CO}_{2}$ combining capacity of 15 volumes per cent or less. Such a test, if reliable, would be of great value. Our experience is that irreversibility to transfusion can exist with $\mathrm{CO}_{2}$ values higher than 15 volumes per cent. Indeed, in most experiments, we found it difficult to keep the animal alive long enough to achieve a level as low as 15 volumes per cent. Whether our use of morphine accounts for this difficulty remains to be determined. However, if care was taken to correct acidosis with the initial transfusion and to maintain a normal or highes than normal $\mathrm{CO}_{2}$ combining capacity thereafter, the deteriorating trend was not noticeably alleviated.

The anoxia of shock, as anticipated, has been found to alter the normal sequence of reactions in carbohydrate metabolism. Phosphorylation of coenzymes (cocarboxylase and cozymase) essential in carbohydrate breakdown and resynthesis is seriously affected $(22,23)$. The lack of substrates normally available for energy release has led to efforts to replace them by others present in tissues but not necessarily serving this purpose, e.g., succinic acid. When some workers (24) showed that this substance in vitro increases oxygen consumption of tissue slices at low oxygen tensions, others $(25,26)$ reported substantial improvement in the shock state as a result of its administration. We were unable to substantiate these claims in tourniquet shock (27) or in hemorrhagic shock (Group E). Recently, it has been found $(28,29)$ that the increased oxygen consumption at low oxygen tensions is produced by succinic acid at the expense of the tissue and to that extent succinic acid can be regarded as deleterious rather than helpful. 
The tolerance of the organism to hemorrhage, when the latter is induced by the withdrawal of blood by simple needle puncture of a large artery in the intact unanesthetized and unimmobilized dog, contrasts sharply with that of the dog anesthetized, immobilized, cannulated, and otherwise traumatized. This points up the need of excluding as far as possible all extraneous factors, if the shock due to hemorrhage alone is to be properly evaluated. The more such factors are eliminated, the more difficult it becomes to produce irreversibility to transfusion, which is achieved by prolonging the time and increasing the degree of hypotension. Our experiments approached the ideal of simplification only very approximately, for we used morphine and open wounds and a considerable degree of immobilization in order to obtain essential data not otherwise possible. The factor of sepsis is, however, of dubious import, because of the absence of pathological evidence of its presence in these experiments, and because the experimental period seems too short for the production of significant amounts of bacterial toxin. Even if bacteremia is common in these circumstances, it remains to be shown that the kind of organisms and their number and their virulence were of sufficient consequence during the period of experimentation to have influenced the results. Reduced to the simplest conditions it is possible to achieve experimentally, we believe that the course of events in hemorrhagic shock leading to the development of a state of irreversibility to transfusion is a function of the severity and duration of inadequate capillary flow, with a cumulative adverse effect on the integrity of function of one or more vital organs, such as the liver, or of a basic biochemical process dependent on cellular integrity over a wider area.

The almost immediate precipitation of typical traumatic shock by a potent toxin (30) without a significant fall in blood volume represents a condition analogous to that of the animal in hemorrhagic shock which is irreversible to transfusion. Shock due to such a toxin may be regarded merely as a variant of hemorrhagic shock in the sense that the disruption of cellular integrity is effected immediately by a toxin rather than gradually by the progressive effects of anoxic damage.

Objections have been made to our employing as a test of irreversibility the failure of the transfusion of all shed blood to reverse the course of the shock process, because, when such a transfusion is given, some dogs will have deteriorated to a greater degree than others; that is to say, that some will be so to speak " 10 per cent dead" and others "90 per cent dead" when the blood is returned. Certainly a more convenient test of irreversibility would be desirable, but no reliable one is available. We could wish for more uniformity in the degree of deterioration than we achieve, but this would be possible only if we had some reliable physiologic or biochemical measurement to detect the onset of irreversibility. A certain limitation to the degree of deterioration is obtained by testing the therapeutic agent only in such dogs as show a good response to transfusion before relapsing into shock. A permanently sustained response to transfusion constitutes a therapeutic problem which is solved. What we seek is the understanding of and a method of treating that phase of shock which requires something more than blood alone to correct it. This is the therapeutic problem which is unsolved. Even though the organism irreversible to a transfusion is properly characterized as " 10 per cent dead" or "90 per cent dead," it is shock nevertheless and it is the kind of shock that constitutes the existing challenge in therapeusis. To use a less rigid criterion of irreversibility is to accept a less severe test and one, therefore, which is not as safe for testing the effectiveness of any agent aside from the transfused blood itself.

\section{SUMMARY AND CONCLUSIONS}

The therapeutic value of various agents for the treatment of hemorrhagic shock, which is not responsive to the replacement of all shed blood, was tested under conditions calculated to avoid or to minimize the confusing effects of anesthesia, blood sampling, operative manipulations, and other forms of trauma. Utilizing the relatively simplified set of conditions described the following results were observed with the agents tested:

1. Massive infusions of saline may cause transitory improvement in circulation but do not cure hemorrhagic shock irreversible to transfusion.

2. Massive infusions of isotonic bovine albumin greatly increase the blood volume and may sustain 
the circulation for a time, but only rarely result in recovery. A marked bleeding tendency is produced by this therapy. Concentrated (25 per cent) bovine albumin solution in equivalent or greater protein content is of no benefit, even if supplemented by saline solution.

3. Large volume intravenous infusion therapy, using either saline solution alone or albumin in saline solution, is harmful by producing marked edema of tissues, serous effusion, venous distention, and widespread hemorrhage from small vessels.

4. Pitressin, with or without ergotamine, is of no value. The combination of pitressin with 5 per cent albumin solution is not beneficial.

5. Paredrine causes an elevation of the arterial and venous blood pressure and no improvement in cardiac output. The duration of this effect is limited by the rapid development of unresponsiveness to the drug and survival time is not prolonged.

6. Coramine increases skeletal muscle tone, but does not favorably influence the course of events.

7. The correction of acidosis by the administration of sodium bicarbonate with the initial transfusion does not alter the deteriorating trend of advanced hemorrhagic shock.

8. Sodium succinate is of no benefit in the therapy of advanced hemorrhagic shock.

9. Tuamine, given when the initial transfusion is failing, causes a transitory rise in blood pressure but the effect is brief. Survival time is not prolonged.

10. "Potassium phosphate" intra-cisternally did not alter the deteriorating trend of hemorrhagic shock and at the same time produced undesirable cerebral excitatory phenomena.

It is our view that advanced shock constitutes a state of progressive deterioration which is not amenable to the types of therapy now available, probably because fundamental biochemical changes have developed as a result of prolonged deficiency of capillary flow. These changes may result from injury predominantly involving one vital organ, such as the liver, or from widespread cellular damage.

Acknowledgment is due Miss Martha Goldberg and Mrs. Shiffre Shactman for technical assistance.

\section{BIBLIOGRAPHY}

1. Lamson, P. D., Personal communication.

2. Fine, J., and Seligman, A. M., Traumatic shock. IV. A study of the problem of the "lost plasma" in hemorrhagic shock by the use of radioactive plasma protein. J. Clin. Invest., 1943, 22, 285.

3. Fine, J., and Seligman, A. M., Traumatic shock. An experimental study including evidence against the capillary leakage hypothesis. Ann. Surg., 1943, 118, 238.

4. Fine, J., and Seligman, A. M., Traumatic shock. VII. A study of the problem of the "lost plasma" in hemorrhagic, tourniquet, and burn shock by the use of radioactive iodo-plasma protein. J. Clin. Invest., 1944, 23, 720.

5. Allen, F. M., Experiments on theory and therapy of shock. Arch. Phys. Therapy, 1943, 24, 327.

6. Warren, J. V., Merrill, A. J., and Stead, E. A., Jr., Rôle of extracellular fluid in maintenance of normal plasma volume. J. Clin. Invest., 1943, 22, 635.

7. Moyer, C. A., Coller, F. A., Job, V., Vaugham, H. H., and Marty, D., A study of the interrelationship of salt solutions, serum and defibrinated blood in the treatment of seventy scalded, anesthetized dogs. Ann. Surg., 120, 367, 1944.

8. Wiggers, C. J., and Werle, J. M., Cardiac and peripheral resistance factors as determinants of circulatory failure in hemorrhagic shock. Am. J. Physiol., 1942, 136, 421.

9. Page, I. H., Unpublished observations.

10. Henderson, Y., Tonus and venopressor mechanism: the clinical physiology of a major mode of death. Medicine, 1943, 22, 223.

11. Frank, H. A., Altschule, M. D., and Zamcheck, N., Traumatic shock. IX. Pressor therapy. The effect of paredrine (p-hydroxy-a-methylphenylethylamine hydrobromide) on the circulation in hemorrhagic shock in dogs. J. Clin. Invest., 1945, 24, 54.

12. Gunther, L., Engelberg, H., and Strauss, L., Intramuscular pressure. II. The venopressor mechanism in shock-like conditions and the effects of various drugs. Am. J. M. Sc., 1942, 204, 271.

13. Zweifach, B. W., Lee, R. E., Hyman, C., and Chambers, $R$., Omental circulation in morphinized dogs subjected to graded hemorrhage. Ann. Surg., 120, 232, 1944.

14. Chambers, R., Personal communication.

15. Van Slyke, D. D., Personal communication.

16. Russell, J. A., Long, C. N. H., and Wilhelmi, A. E., IV. The oxygen consumption of liver and kidney tissue from rats in hemorrhagic shock. J. Exper. Med., 79, 23, 1944.

17. Frank, H. A., Seligman, A. M., and Fine, J., Traumatic shock. XIII. The prevention of the development of "irreversible" hemorrhagic shock by viviperfusion of the liver. To be published.

18. Goldberg, M., and Fine, J., Traumatic shock. XI. Intestinal absorption in hemorrhagic shock. J. Clin. Invest., 1945, 24, 445. 
19. Meyer, R. K., and Potter, V. R., Personal communication.

20. Cannon, W. B., The course of events in secondary wound shock. J. A. M. A., 1919, 73, 174.

21. Levine, R., Huddlestun, B., Persky, H., and Soskin, S., The successful treatment of so-called "irreversible" shock by whole blood supplemented with sodium bicarbonate and glucose. Am. J. Physiol., 1944, 141, 209.

22. Alexander, B., Tissue thiamine in hemorrhagic shock. J. Clin. Invest., 1944, 23, 259.

23. Govier, W. M., and Greer, E. M., Personal communication.

24. Shorr, E., Personal communication.
25. Mylon, E., Winternitz, M. C., and de Süto-Nagy, G. J., Studies on therapy in traumatic shock. Am. J. Physiol., 1943, 139, 313.

26. Soskin, S., Personal communication.

27. Fine, J., Frank, H. A., and Seligman, A. M., Traumatic shock. VIII. Studies in the therapy and hemodynamics of tourniquet shock. J. Clin. Invest., 1944, 23, 731.

28. Shorr, E., Personal communication.

29. Meyer, R. K., and Potter, V. R., Personal communication.

30. Freedberg, A. St., Haimovici, H., and Blumgart, $H$. L., The cardiovascular dynamics in shock due to Shiga toxin. In preparation. 